\title{
An Urban Charging Infrastructure for Electric Road Freight operations: A case study for Cambridge UK
}

\author{
Doros Nicolaides, Member of IEEE, David Cebon, John Miles
}

\begin{abstract}
An urban charging infrastructure for electric road freight operations is explored in this paper. The city of Cambridge UK was chosen for demonstration but the same methodology could be used for other cities. The five Park and Ride bus routes, the refuse collection operations and two home delivery operations are investigated. Data about existing operations were collected to define accurate drive cycles. Different vehicles are modelled for each operation and their performance is evaluated over the defined drive cycles. Different charging infrastructures are proposed for each operation to ensure that electric freight vehicles can be used for similar duty cycles as conventional vehicles. The additional power demand, additional load, capital cost needed and the $\mathrm{CO}_{2}$ emissions savings for each case are calculated. The results are scaled up for the entire city and combined with estimated performance requirements for electrified urban deliveries. A complete urban charging network for road freight transportation at Cambridge would increase the power demand of the city by 21.6 MW (20.4\% of the current peak) and the energy consumption by $50.6 \mathrm{GWh}$ per year $(6.3 \%$ of current consumption). The total capital cost is calculated at $£ 149$ million which is similar to the cost of other city's projects.
\end{abstract}

Index Terms - buses, charging infrastructure, electric vehicles, freight, home deliveries, power demand, refuse collection

\section{INTRODUCTION}

It has been generally accepted that decarbonisation of the transport sector is a necessary step towards alleviating climate change. The shift towards electric vehicles (EVs) has been identified as one of the most beneficial approaches for achieving this target since significant reduction of $\mathrm{CO}_{2}$ emissions in comparison with conventional vehicles can be achieved when the electricity grid is decarbonised [1]. In addition, EVs offer zero tailpipe emissions, eliminating the release of noxious pollutants. Aspirations for better air quality coupled with low operational noise make EVs an attractive solution particularly for urban areas, e.g. [2].

Substantial progress towards more sustainable transport requires a significant contribution from the freight sector which accounts for approximately $33 \%$ of road transport emissions in Great Britain (GB) [3]. Deep decarbonisation of road freight by conventional means is difficult. Strategies for that purpose can include a wide range of measures including improvements to aerodynamics, higher capacity vehicles, driver performance, regenerative braking, etc. Combination of these measures

$\mathrm{M}_{\text {anuscript submitted }}$

D.Nicolaides is with the Department of Engineering, University of Cambridge UK (e-mail: $\underline{\text { dn314@ @am.ac.uk) }}$ should be capable of reducing fuel consumption and $\mathrm{CO}_{2}$ emissions approximately by $30 \%$ [4], [5]. For $\mathrm{CO}_{2}$ emission reductions beyond that level, alternative energy sources need to be investigated.

A recent study conducted by the authors has shown that shifting towards electric freight vehicles would be technically feasible [6]. A logistics concept was proposed, that could be used in conjunction with current and future electrification technologies, to provide a framework for the electrification of most road freight transport operations. Based on that, simulation tools and methods were presented to set the performance requirements for a practical system. Finally, four case studies were developed for assessing the feasibility of electrification of various road freight operations, including Long-Haul Journeys, Urban Deliveries, Home Deliveries and Refuse Collection.

It was shown that long-haul journeys would require installation of a charge-on-the-move network on GB's motorways. Such infrastructure appears to be technically and financially feasible and it could be significant driver for substantial $\mathrm{CO}_{2}$ emissions reductions in the long-term [7]-[10]. Yet, extensive road infrastructure modifications are needed.

A shorter-term solution is the electrification of road freight operations within the boundaries of a city. Road freight could be transported by battery-powered EVs that charge their batteries while loading at depots and could potentially top-up at charging points while unloading, e.g. at convenience stores. Other heavy vehicles operating within the area of cities, such as buses and refuse collection vehicles, could top-up their batteries from charging points distributed at key locations along their routes. This 'charge-on-the-stop' (CoS) approach, reduces significantly the necessary battery capacity and vehicle costs which makes the shift towards EVs possible. It also distributes the charging process geographically, reducing the need for very large charging facilities in few locations.

Power charging systems for EVs have been under development for some decades. Conductive systems are well established and have high efficiency and reliability. Nonconductive (wireless) chargers suitable for EVs have also been developed and high efficiencies, over $90 \%$, can be obtained for static charging applications [11]-[13]. The ability to avoid plug-in cables and to use simple systems that are unaffected by

D. Cebon is with the Department of Engineering, University of Cambridge UK (e-mail: dc@eng.cam.ac.uk)

J. Miles is with the Department of Engineering, University of Cambridge UK (e-mail: jcm91@eng.cam.ac.uk) 
weather conditions is likely to be attractive to drivers and cities.

High power transfer rates have been achieved, which makes wireless chargers relevant to road transport operations performed by freight vehicles, buses and refuse collection vehicles. For example, $120 \mathrm{~kW}$ wireless chargers are used in Milton Keynes where electric buses receive a $10 \mathrm{~min}$ booster charge at wireless charging points located at either end of Route 7 [14]. In addition, 150-600 kW conductive overhead catenary systems suitable for electric buses have been developed by SIEMENS and ABB for en-route opportunity charging at the stop [15], [16].

This study explores the electrification of road freight operations within the boundaries of a city, including the auxiliary services of buses and refuse collection functions. The city of Cambridge UK has been chosen for demonstration. The local council is keen to promote the adoption of emerging technologies and solutions towards more sustainable cities, as disclosed by the recent introduction of the 'Smart Cambridge' programme [17]. Nevertheless, the methodology presented in this study could be considered as a framework to assess the prospects of electric freight operations in other cities as well.

The five 'Park and Ride' bus routes of the city, the refuse collection operations and two home delivery operations were investigated. Operational data about speed, location and engine performance, were used to define accurate drive cycles and validate simulations. A vehicle simulation tool was used to estimate the power requirements of EVs over the defined drive cycles. The performance requirements for a practical system were set and an appropriate charging infrastructure for the city was proposed. The number and location of charging points required within the city, their power transfer rates and the capacity of the on-board battery for each vehicle were determined by solving an optimisation problem. The additional power demand for such a system was calculated and the implications for the electricity supply network were explored. A cost model was also built to assess the financial viability of the infrastructure. The results were then combined with estimated performance requirements for electrified urban deliveries at Cambridge to explore the impacts from a complete urban charging network for road freight operations in the city.

This study presents innovative results for academia, industry and government. Electrification of urban road freight transportation is a viable strategy for more sustainable transportation that could make a big difference in the future. Previously it was thought that electrification of road freight might not be a practical approach for achieving the deep levels of decarbonisation needed in the long-term. This was mainly because of the high energy demands of the vehicles, the implications for the electricity supply network and the cost required for deploying the necessary charging infrastructure. This study shows that this view is not correct. Large and expensive on-board batteries are not required for operation within the proposed solutions and recharging times are limited to minimum. Investment is needed for the development of charging infrastructure but it is shown that these costs are comparable to other urban infrastructure projects.

\section{Methodology}

In this section, the methods of data collection, the simulation tools used in the study and the process for selecting en-route charging points are described.

\section{A. Data collection}

An electronic logging device, developed in the Department of Engineering University of Cambridge for the Centre for Sustainable Road Freight (SRF), was used for logging the routes of buses and delivery vans. The device, known as 'SRF Logger', is based on a mobile phone which is connected to the vehicle using one of the vehicle's standardised diagnostic ports. The SRF Logger starts collecting data automatically without intervention of the driver, when the vehicle's engine starts. All stored data is transmitted wirelessly to a server located in the Department of Engineering. Limited data was also collected using the GPS signal of the device (GPS location and speed) without connecting it to the vehicle. This was particularly useful for logging operations quickly as installation in the vehicle was not needed. However, the user had to physically ride the route under investigation.

For the case of refuse collection operations, a tracking device was already installed on the vehicles. Real-time data for each vehicle was available in an online database, including information about time, GPS location, speed and the operational status of the bin lift and compaction systems [18].

\section{B. Simulation Tools}

The 'Advanced Vehicle Simulator' (Advisor) was used to estimate the power requirements of EVs. Advisor is an open source software tool that was developed at the National Renewable Energy Laboratory for the US Department of Energy [19]. Its accuracy has been validated by several authors and laboratories [20], [21]. The user models the vehicle of interest and investigates the characteristics of the journey over specific drive cycles, such as the required power from the electric motor, the state of charge of the on-board battery, etc.

Different EVs were modelled for each operation using Advisor. These were: 1) 'eBus', 2) 'eVan' and 3) 'eRCV' for electric buses, electric delivery vans and electric refuse collection vehicles respectively [19]. Standard vehicles provided by Advisor were adjusted appropriately and values were determined for the power rating of electric motors, constant electrical loads (e.g. refrigeration, bin lifting, etc.) and the overall masses of the vehicles. The final parameter values are summarized in TABLE 1 . The capacity of the on-board battery of each vehicle is dependent on the proposed charging infrastructure as designed below. Lithium-Ion batteries, predominantly used in EVs [22], were assumed in the simulation models.

TABLE 1

COMPONENTS OF SIMULATED EVS

\begin{tabular}{llccc}
\hline \hline & \multicolumn{1}{c}{ Advisor's vehicle model } & $\begin{array}{c}\text { Motor } \\
(\mathrm{kW})\end{array}$ & $\begin{array}{c}\text { Load } \\
(\mathrm{kW})\end{array}$ & $\begin{array}{c}\text { Mass } \\
(\mathrm{kg})\end{array}$ \\
\hline eBus & Orion VI Transit Bus & 150 & 0.5 & 18,000 \\
eRCV & Kenworth T800 Vehicle & 150 & 1 & 26,000 \\
eVan & Full size cargo van & 75 & 2 & 3,500 \\
\hline \hline
\end{tabular}




\section{Selection of charge-on-the-stop points (CoSP)}

A 'Charging Infrastructure' tool was built on top of Advisor to select the most appropriate en-route charging points. It uses the results of the simulations to evaluate each position along the route and creates a ranked list of all possible charge-on-the-stop points (CoSP). The ranking of each location is calculated based on the i) stop duration of each vehicle at each location: vehicles stop longer at bus stops and depots which therefore provide suitable locations for the installation of a CoSP and ii) the distance travelled to reach each location: locations closer to the origin or close enough to other previously selected CoSP get lower priority because they are within the expected mileage range of EVs. The methodology is detailed explained in [23].

The capacity of the on-board battery and the SOC as a function of time/ distance can be calculated, based on the proposed charging infrastructure (i.e. number and power transfer rate of CoSP). The maximum power transfer capability of each CoSP was set at $200 \mathrm{~kW}$. The required minimum SOC and the maximum allowed charge rate (C) were chosen as $20 \%$ and $1.5 \mathrm{C}$ respectively for maximising the life span of the onboard batteries [24]. The tool ignores any instantaneous charging boosts and allows half a minute lost charging time at each stop due to any alignments requirements and 'build up' of current in the power electronics. It also takes into consideration any over-charging situations.

\section{CASE Study: Buses}

Buses perform journeys on predefined routes and specified timetables. This allows researchers to analyse precisely the performance of the vehicles and calculate their energy requirements over these journeys.

The five Park and Ride bus routes in the city of Cambridge UK were chosen to investigate the procedure. The routes are the 1) Trumpington, 2) Newmarket, 3) Milton, 4) Madingley and 5) Babraham, which all run within the boundaries of Cambridge, as shown in Fig 1.

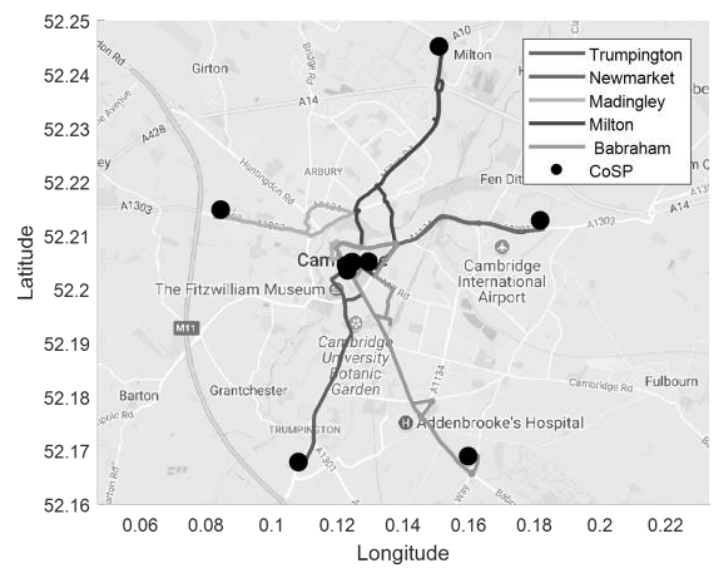

Fig 1. Park and Ride bus routes at Cambridge UK with the chosen CoSP

The 'bus graphs' were then derived from publicly available timetable. The graphs show the size of the fleet and the duty cycle of each bus including journeys from the depot to the first bus stop. The Trumpington route involves four buses with up to $220 \mathrm{~km}$ maximum mileage per day (see TABLE 2).

\section{A. Energy requirements}

The author physically rode the buses under investigation, which are all Double Decker, and logged the GPS coordinates and speed profiles of the routes using the SRF Logger. The elevation profile was also calculated from the GPS coordinates using Google Maps. The logged drive cycle of the Trumpington Park and Ride route is shown in Fig 2. The bus departs from the city centre at 10.30 and arrives at the Trumpington Park and Ride stop at 10:47. It then returns back to the city centre after a $3 \mathrm{~min}$ stop. The length of this trip was computed at $9.3 \mathrm{~km}$.

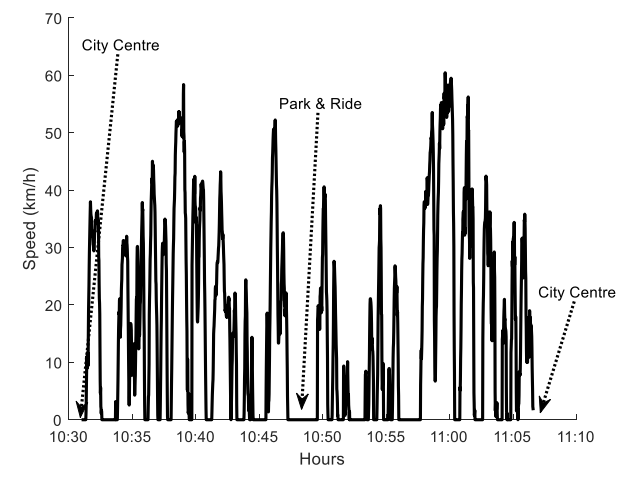

Fig 2. Trumpington Park and Ride logged drive cycle

The performance of the modelled eBus (TABLE 1) was simulated over the defined duty cycles using Advisor. The duty cycles were defined using real data from existing operations, measured using the SRF logger. Data was recorded during different days and times to identify any potential discrepancies on power requirement and energy consumption. This means that information about traffic and driver behaviour are included inherently in the logged drive cycles.

The simulation produces a variety of output quantities. For EVs these include the target and actual speeds of the vehicle through the driving cycle, the power required from the electric motor to track the drive cycle and the battery SOC versus time/distance. The speed, power and energy are calculated by the Advisor simulation according to the parameters of the vehicle and driving cycle under investigation.

The average energy consumption of the Trumpington Park and Ride route was calculated at $1.7 \mathrm{kWh} / \mathrm{km}$. TABLE 2 summarises the energy requirements of all Cambridge Park and Ride bus routes.

TABLE 2

BUS ROUTES - DRIVE CYCLES AND ENERGY REQUIREMENTS

\begin{tabular}{l|ccc|cc}
\hline \hline & \multicolumn{3}{|c|}{ Based on Bus graphs } & \multicolumn{2}{c}{ Advisor } \\
\cline { 2 - 6 } & $\begin{array}{c}\text { Num. of } \\
\text { buses }\end{array}$ & $\begin{array}{c}\text { Distance per bus }(\mathrm{km}) \\
\text { Trip }\end{array}$ & Max Daily & $\begin{array}{c}\text { Avg. } \\
\text { Speed } \\
(\mathrm{km} / \mathrm{h})\end{array}$ & $\begin{array}{c}\text { Energy } \\
(\mathrm{kWh} / \mathrm{km})\end{array}$ \\
\hline Trumpington & 4 & 9.3 & 220 & 15.8 & 1.7 \\
Newmarket & 4 & 10.5 & 300 & 18.2 & 1.4 \\
Madingley & 3 & 9.7 & 390 & 18.2 & 1.6 \\
Milton & 4 & 12.2 & 325 & 15.9 & 1.5 \\
Babraham & 5 & 12.1 & 335 & 10.9 & 1.4 \\
\hline \hline
\end{tabular}

TABLE 3 shows the energy requirements per day for each bus route as function of the number of buses on each route. It is noticed that the energy requirements per day varies for each bus on the same route because they perform slightly different daily duty cycles as a result of the bus graphs. The capacity of the on- 
board battery needed without any charging boosts en-route was calculated based on the most demanding bus of each route. A $20 \%$ safety margin was considered for maximising the life span of the batteries. It can be seen that very large batteries would be needed if there are no CoSPs, particularly for the Madingley route which would need batteries of $755 \mathrm{kWh}$.

TABLE 3

BUS FLEET, ENERGY REQUIREMENTS AND SIZE OF BATTERY

\begin{tabular}{lccccc}
\hline \hline & Trumpi. & Newm. & Madin. & Milton & Babra. \\
\hline Daily energy (kWh) & 1,380 & 1,610 & 1,750 & 1,850 & 2,015 \\
Bus 1 & 370 & 390 & 605 & 440 & 455 \\
Bus 2 & 320 & 425 & 540 & 440 & 405 \\
Bus 3 & 370 & 370 & 605 & 485 & 350 \\
Bus 4 & 320 & 425 & - & 485 & 375 \\
Bus 5 & - & - & - & - & 430 \\
Battery $(k W h)$ & 460 & 530 & 755 & 605 & 570 \\
\hline \hline
\end{tabular}

\section{B. Trumpington Park and Ride}

In this section, the concepts of Overnight Charging (OnC) and charge-on-the-stop (CoS), usually known as 'opportunity charging', are investigated through a case study for the Trumpington Park and Ride route. For the former, buses are equipped with a battery big enough to supply the energy requirements for the entire day. The batteries get recharged overnight when the vehicles return back to the depot. In contrast, smaller batteries are used when opportunity charging is available because the buses get multiple small charging boosts during operation from CoSP installed along their routes. The stored energy on-board is shown in Fig. 3 for both electrification options for the Trumpington Park and Ride route. A $460 \mathrm{kWh}$ battery and a $65 \mathrm{kWh}$ battery are needed for the $\mathrm{OnC}$ and $\mathrm{CoS}$ approaches respectively. For the CoS solution, a $100 \mathrm{~kW}$ charger is installed at either end of the route.

Both approaches have advantages and drawbacks. The main advantage of the OnC solution is that vehicles do not depend on the infrastructure of the specific route. The bus operator can potentially use the same buses for various routes. However, the large batteries needed introduce significant practical and engineering issues that undermine the feasibility of the system. The specific energy of Lithium-Ion batteries predominantly used in EVs is approximately $8 \mathrm{~kg} / \mathrm{kWh}$ [22]. This means that the $460 \mathrm{kWh}$ battery needed for the Trumpington Park and Ride route (including the 20\% safety margin) adds $3 \mathrm{t}$ to the vehicle; reaching an overall mass of approximately $21 \mathrm{t}$. This assumes a $400 \mathrm{~kg}$ saving from the lighter electric motor and transmission system (obtained from Advisor's components) and a $300 \mathrm{~kg}$ saving from not carrying the 300 litre fuel tank of DoubleDecker buses. This mass is well above the maximum gross mass of $18 \mathrm{t}$. As a result, the bus operator would need to reduce the number of passengers on-board to avoid exceeding the maximum load limit. The additional mass of $3 \mathrm{t}$ corresponds to approximately 40 passengers (one deck), assuming an average weight of $75 \mathrm{~kg}$ per person. Furthermore, the massive size of the battery imposes technical concerns because the largest battery that has been used in the automotive industry to date is $324 \mathrm{kWh}$, on the BYD eBuses [25].

The $\mathrm{CoS}$ approach eliminates the problems related with the massive batteries. An eBus with the necessary $65 \mathrm{kWh}$ battery on-board would be lighter than a conventional bus by approximately $200 \mathrm{~kg}(65 \mathrm{kWh} \mathrm{X} 8 \mathrm{~kg} / \mathrm{kWh}-400 \mathrm{~kg}-300 \mathrm{~kg})$. Having distributed charging also dramatically reduces the charging infrastructure needed at the depot and the charging bottleneck cause by having to charge many buses overnight, as described later.

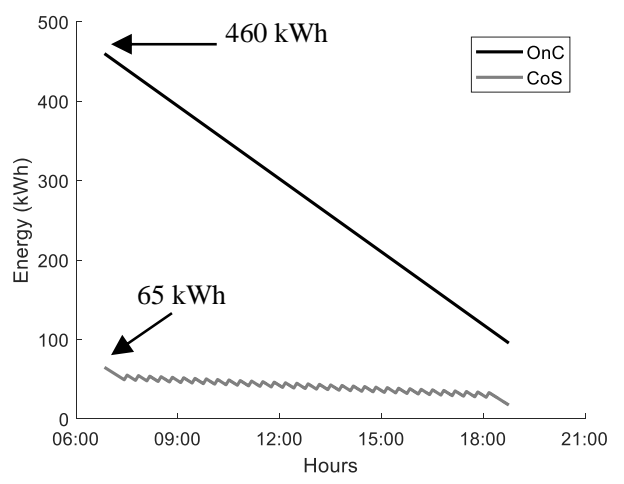

Fig. 3. Trumpington route - Energy diagrams for the OnC and CoS options

The number of CoSP and the capacity of the on-board battery is a major trade-off in the design of a charging infrastructure for eBuses. This concept is revealed in Fig. 4 which shows the number of CoSP installed en-route relative to the capacity of the on-board battery. The size of the battery drops significantly whilst introducing additional CoSP. Yet, it quickly reaches saturation, mainly because the buses only stop long enough for significant charging at either end of their route (see Fig 2). The charging boost at other locations is not enough to reduce the capacity of the battery.

The total capital cost of the system was calculated from the cost of EVs and their batteries plus the charging infrastructure, which includes the cost of equipment, installation and grid connection. The purchase and connection of the chargers needed at the depot are considered as well. Most of the cost figures were obtained from the Milton Keynes Electric Bus project [14]. Additional cost sources were also wireless charging systems that have been commercially available like the INTIS [26], Plugless [27] and BMW systems [28]. The cost assumptions are summarised in TABLE 4 . The results shown in Fig. 5 indicate that the most cost-effective option for the Trumpington bus route is the installation of two CoSP (one at either end of the route) combined with a $65 \mathrm{kWh}$ battery.

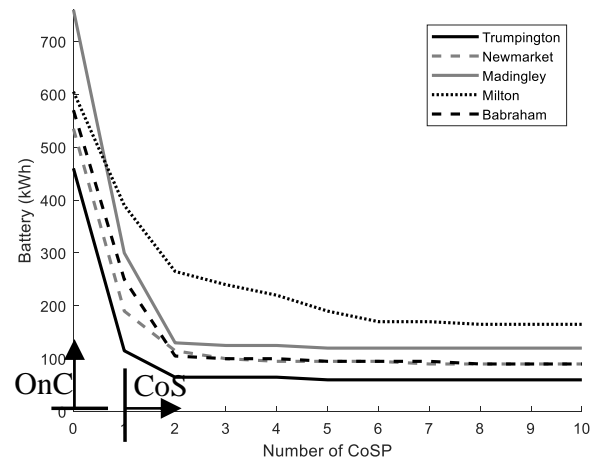

Fig. 4. Park and Ride routes Battery capacity vs Number of CoSP 


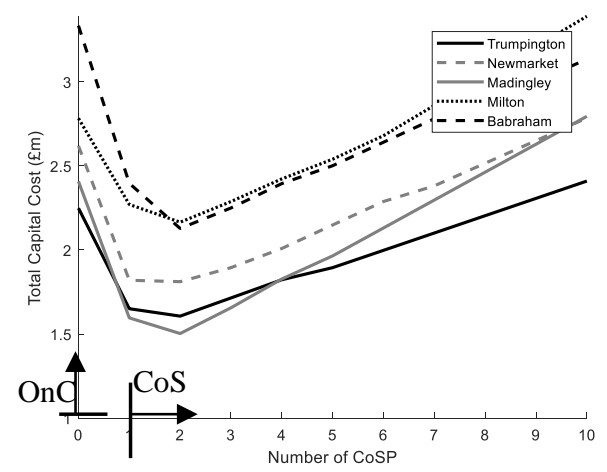

Fig. 5. Park and Ride routes - Capital Cost vs Number of CoSP

TABLE 4

COST ASSUMPTIONS FOR URBAN OPPORTUNITY CHARGING

\begin{tabular}{|c|c|c|}
\hline & $£ \mathrm{k}$ & Notes \\
\hline \multicolumn{3}{|l|}{ Vehicles } \\
\hline eBus & 375 & $\begin{array}{l}\text { Including a } 150 \mathrm{kWh} \text { battery, receiving } \\
\text { unit and power electronics }\end{array}$ \\
\hline Battery & 0.5 & Per extra kWh [14], [22] \\
\hline \multicolumn{3}{|c|}{ Infrastructure - CoSP } \\
\hline Installation & 20 & Per CoSP [14] \\
\hline Equipment & 0.7 & Per kW peak power [14], [26]-[28] \\
\hline Grid connection & 20 & Per CoSP [14] \\
\hline \multicolumn{3}{|c|}{ Infrastructure - Depot } \\
\hline Chargers & 10 & Per charger up to $20 \mathrm{~kW}$ [14], [29] \\
\hline Grid connection & 40 & less than $200 \mathrm{~kW}$ is needed [14] \\
\hline Grid connection & 200 & More than $200 \mathrm{~kW}$ is needed [14] \\
\hline
\end{tabular}

The charging infrastructure of an OnC solution includes only chargers at the depot. The battery energy of the most demanding bus of the route is shown in Fig. 3 with the dark line. It returns to the depot with $95 \mathrm{kWh}$ stored energy $(20 \%$ of the $460 \mathrm{kWh}$ battery) where has to get fully recharged within a minimum period of 7 hours, taking into consideration 3 hours for cleaning and maintenance. At least $55 \mathrm{~kW}$ power chargers are needed per vehicle at the depot to fully recharge the $460 \mathrm{kWh}$ batteries. The daily power demand profile is shown in Fig. 6. It is constant at $220 \mathrm{~kW}$ for most of the night hours and drops to zero when all four buses leave the depot in the morning. Then it gradually increases in the evening as buses return to the depot. An upgrade to the electricity supply at the depot would be needed to meet the additional demand of $220 \mathrm{~kW}$ (4 buses X $55 \mathrm{~kW}$ ).

The CoS infrastructure includes two CoSP at either end of the route and less powerful chargers at the depot. The saw-tooth diagram for this option is shown in Fig. 3 with the grey line where the vehicle gets multiple charging boosts throughout the day. The two CoSP are rated at $100 \mathrm{~kW}$, since a maximum $1.5 \mathrm{C}$ was assumed for maximising the life span of the battery. The bus performing the most demanding route returns to the depot with $27 \%$ SOC. $7 \mathrm{~kW}$ chargers are needed in the depot to fully recharge the $65 \mathrm{kWh}$ batteries overnight. The power demand profile of this electrification solution (shown in Fig. 6) is constant at $28 \mathrm{~kW}$ at early morning and evening hours when the four buses are in the depot. Over the day, the power demand is a rectangular wave because the 2 CoSP deliver power

\footnotetext{
${ }^{1}$ The Department for Business, Energy and Industrial Energy in the UK estimates that the average cost for every generated $\mathrm{kWh}$ would be $£ 0.09$ on average after 2020 [41]. This combined with a typical profit margin for
}

intermittently. For the case of Trumpington Park and Ride route this is every $5 \mathrm{~min}$. Each CoSP delivers a maximum power of $100 \mathrm{~kW}$ but simultaneous operation at either end of the route demands up to $200 \mathrm{~kW}$ power from the electricity network of the city. No upgrade is required to the electricity grid of the depot for meeting the additional demand of $28 \mathrm{~kW}$.

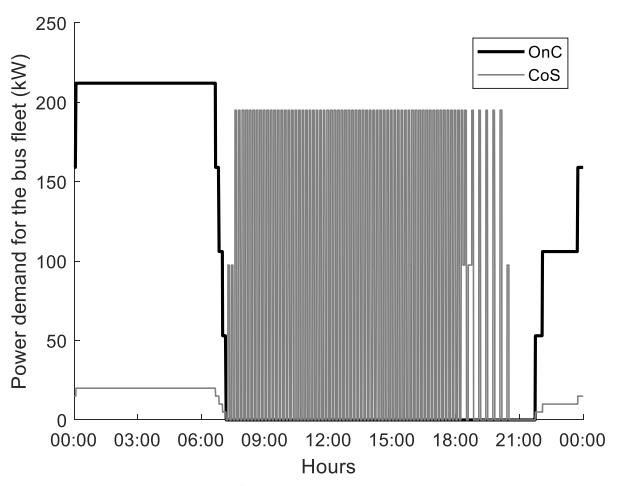

Fig. 6. Power demand of the Trumpington Park and Ride route

OnC is financially less attractive than CoS, mainly due to the capital cost of the massive batteries required on-board (Fig. 5). However, it is possible that electricity prices for OnC might be more attractive than prices during the day (due to commercial or government subsidies); a possible incentive for using power overnight to help balance the load on the grid and maximise usage from renewable energy sources like wind.

To this end, the total costs of an electrified system is calculated, including capital, maintenance and operating costs, to examine whether an $\mathrm{OnC}$ system could be financially more attractive than a $\mathrm{CoS}$ system due to lower operating costs. The cumulative annual expenditures of an electrified system are shown in Fig. 7 for three cases: i) OnC based on the current grid electricity price, ii) $\mathrm{OnC}$ combined with zero electricity costs and iii) $\mathrm{CoS}$ solution ( $2 \mathrm{CoSP}$ ) at current grid electricity costs. The annual expenditures are calculated using the following expression:

Annual expenditures

$$
\begin{aligned}
& =\frac{\text { Capital cost } X \text { Rate }}{1-(1+\text { Rate })^{- \text {Years }}} \\
& + \text { Maintentance cost }+ \text { Operating cost },
\end{aligned}
$$

where a $3 \%$ interest rate over a ten-year payment period is assumed. Maintenance accounts 5\% of the annual spend on capital cost and operating costs are calculated according to the use and price of electricity. The annual energy requirement for the Trumpington route is about $500 \mathrm{MWh}$, as the daily energy needed was calculated at $1,380 \mathrm{kWh}$ (TABLE 3). This combined with a $£ 0.10$ electricity price per $\mathrm{kWh}^{1}$ result in an annual cost of $£ 50 \mathrm{k}$ for operating purposes and $£ 500 \mathrm{k}$ over the ten-year period - this was assumed as zero for the second scenario which involves zero electricity costs. Overall, an electrified bus system for the Trumpington Park and Ride route would cost $£ 3.3$ million in total over the ten-year period for the OnC solution, £2.8 million for the OnC solution combined with zero operating costs and $£ 2.5$ million for the CoS solution.

supplying electricity in the UK around 5-10\% [42], allows us to assume a wholesale price of electricity at $£ 0.10$ per $\mathrm{kWh}$. 


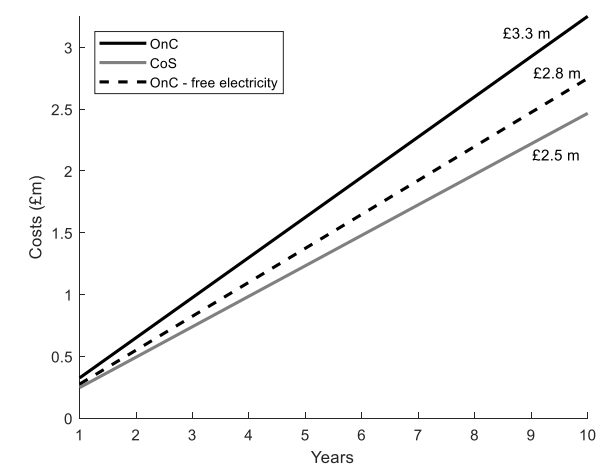

Fig. 7. Annual outcomes over a 10-year lifetime period

It is apparent that the potential operating savings from an OnC system, even if electricity is available for free overnight, are not sufficient to reach the lower expenditures of a $\mathrm{CoS}$ system. The total expenditure is the same for the two systems when the cost of battery drops from $£ 500$ per $\mathrm{kWh}$ (used in this study) as low as $£ 100$ per $\mathrm{kWh}$. However, BYD, one of the largest manufactures of electric buses with $324 \mathrm{kWh}$ on-board batteries, estimates that the battery cost for heavy-duty vehicles by 2025 would be no less than $£ 445$ per kWh [22]. Besides, the OnC buses would have restricted passenger capacity of approximately 40 passengers instead of 90 because of the battery mass. This would require twice as many buses to maintain the same passenger capacity which means that the system would require twice as much energy and would introduce considerable additional capital cost.

It is worth mentioning that the $\mathrm{OnC}$ method does not gain any benefits from lower electricity prices generated by solar energy; because solar energy is available during the day and $\mathrm{OnC}$ is performed overnight. Lower electricity prices from solar energy would reduce the operating costs of $\mathrm{CoS}$ which means that $\mathrm{OnC}$ can be shown to be an even less attractive approach.

\section{City's Park and Ride bus routes}

The same analysis was conducted for all Park and Ride bus routes at Cambridge (Fig. 4 and Fig. 5). The results are summarised in TABLE 5, for the two electrification options. Such a charging infrastructure is shown in Fig 1 where a CoSP is installed at either end of each bus route.

TABLE 5

PARK AND RIDE BUS ROUTES ELECTRIFICATION SOLUTIONS

\begin{tabular}{lccccc}
\hline \hline & $\begin{array}{c}\text { Ondtery } \\
(\mathrm{kWh})\end{array}$ & $\begin{array}{c}\text { Cost } \\
(£ \mathrm{~m})\end{array}$ & $\begin{array}{c}\text { Battery } \\
(\mathrm{kWh})\end{array}$ & $\begin{array}{c}\text { CoS } \\
\text { CoSP } \\
(\mathrm{kW})\end{array}$ & $\begin{array}{c}\text { Cost } \\
(£ \mathrm{~m})\end{array}$ \\
\hline Trumpington & 460 & 2.2 & 65 & 100 & 1.6 \\
Newmarket & 530 & 2.6 & 115 & 175 & 1.8 \\
Madingley & 755 & 2.4 & 130 & 195 & 1.5 \\
Milton & 605 & 2.8 & 265 & 200 & 2.1 \\
Babraham & 570 & 3.3 & 105 & 160 & 2.1 \\
Total & - & 13.3 & - & - & 9.1 \\
\hline \hline
\end{tabular}

The power demand for all Park and Ride bus routes at Cambridge was then calculated. The daily profiles have similar trends to the power demand of the Trumpington Park and Ride bus route shown in Fig. 6. The peak power demand for OnC of all cities' Park and Rides buses reaches 1,400 kW during the early morning and late evening hours. It remains zero throughout the day because all the power is needed overnight at the depot. The daily profile of the $\mathrm{CoS}$ for all routes shows that $255 \mathrm{~kW}$ is needed at the depot overnight. Throughout the day, the power demand fluctuates up to $1,300 \mathrm{~kW}$ as multiple CoSP become active at different locations within the city.

The peak power demand of GB was around $53 \mathrm{GW}$ in the winter of 2017-2018 [30]. The city of Cambridge accounts for $0.2 \%$ of the total population of the country; 130 thousand people in Cambridge from a total 65 million people [31]. Assuming that the peak power demand at Cambridge is $0.2 \%$ of that of GB, the peak power demand of Cambridge is estimated at $106 \mathrm{MW}$. In addition, the electricity consumption of Cambridge was assumed at an annual $800 \mathrm{GWh}$. This also corresponds to $0.2 \%$ of the total $400 \mathrm{TWh}$ GB's electricity consumption in 2015 [32].

The new peak power demand up to $1.4 \mathrm{MW}$, due to the electrification of all Park and Ride bus routes at Cambridge, represents an additional demand of $1.3 \%$. In terms of energy, the electrified bus routes need 8.6 MWh per day, as this can be derived from TABLE 3 . This corresponds to an annual energy consumption of 3,141 MWh which represents an insignificant additional load of only $0.4 \%$ based on current figures.

\section{Carbon emissions savings}

Using the eBus model, the fuel economy of an $18 \mathrm{t}$ diesel powered bus was calculated to be $29.41 / 100 \mathrm{~km}$ on average when travelling the five Park and Ride bus routes. About $2.69 \mathrm{kgCO}_{2}$ are produced from burning a litre of diesel fuel [33] which means that a conventional $18 \mathrm{t}$ bus emits $790 \mathrm{gCO}_{2} / \mathrm{km}$. The eBus model consumes an average of $1.42 \mathrm{kWh} / \mathrm{km}$ as this can be derived from TABLE 6 (annual energy over annual mileage). Using the carbon intensity of the UK electricity supply network in 2017 of approximately $300 \mathrm{gCO}_{2} / \mathrm{kWh}$ [34], this corresponds to $430 \mathrm{gCO}_{2} / \mathrm{km}$ and a substantial reduction of $45 \%$. Using DECC's projected $\mathrm{CO}_{2}$ intensity of $100 \mathrm{gCO}_{2} / \mathrm{kWh}$ [35] for the significantly decarbonized UK electricity grid in 2030, the $\mathrm{CO}_{2}$ emissions of the $18 \mathrm{t}$ bus would be only $142 \mathrm{gCO}_{2} / \mathrm{km}$. This corresponds to a very significant reduction of $82 \%$. Using the $\mathrm{CO}_{2}$ intensity of $40 \mathrm{gCO}_{2} / \mathrm{kWh}$ by 2050 [36], reduction of $92 \% \mathrm{CO}_{2}$ emissions is feasible.

The impact of the electrified Park and Ride routes in Cambridge would be to save $805 \mathrm{tCO}_{2}$ per year at today's figures (see TABLE 6). Provided the emission rate for every generated $\mathrm{kWh}$ drops from $300 \mathrm{gCO}_{2} / \mathrm{kWh}$ to $40 \mathrm{gCO}_{2} / \mathrm{kWh}$ by $2050,1,621 \mathrm{tCO}_{2}$ per year could be achieved. This corresponds to accumulated savings of $38 \mathrm{ktCO}_{2}$, assuming a $2.2 \%$ annual increase rate each year between 2018 and 2050 .

TABLE 6

ELECTRIFIED PARK AND RIDE BUS ROUTES ANNUAL OVERVIEW

\begin{tabular}{lcccc}
\hline \multirow{2}{*}{ Energy $(\mathrm{MWh})$} & \multirow{2}{*}{ Mileage $\left(10^{3} . \mathrm{km}\right)$} & \multicolumn{2}{c}{$\mathrm{tCO}_{2}$ savings } \\
& & & 2018 & 2050 \\
\hline Trumpington & 504 & 317 & 115 & 232 \\
Newmarket & 588 & 428 & 156 & 314 \\
Madingley & 639 & 433 & 158 & 317 \\
Milton & 675 & 478 & 174 & 350 \\
Babraham & 735 & 556 & 202 & 408 \\
Total & 3,141 & 2,212 & 805 & 1,621 \\
\hline \hline
\end{tabular}




\section{CASe Study: Refuse Collection Vehicles}

Various categories of refuse collection operations exist at Cambridge. These are i) Domestic Waste, ii) Trade Waste, iii) Dry Recycling, iv) Green Recycling and v) Bin Deliveries. Different vehicles are assigned to each operation. According to Cambridge Waste Management, each vehicle has a two-week duty cycle. Hence, we investigated each vehicle for a two-week period to record all refuse collection routes at Cambridge and design a charging infrastructure for the entire city.

The refuse collection vehicles of the city are equipped with GPS trackers, collecting real-time operational data. Based on this data, the drive cycles were defined along with information about the bin lift and compaction systems. The Advisor eRCV model (TABLE 1) was used for the simulations. A constant load of $2 \mathrm{~kW}$ was included in the simulations to consider the bin lift and compaction procedures and other loads on-board such as safety lights. It was assumed that the vehicle leaves the depot empty (unladen mass at $7 \mathrm{t}$ ). The cargo increases progressively during each shift and this can be modelled using data from the monitored bin lift and compaction functions.

\section{A. Domestic Waste Collection}

Eight refuse collection vehicles are assigned to the domestic waste collection operations in Cambridge. Fig. 8 shows the most energy demanding route of the two-week period. There are parts of the route dedicated for driving between collection areas (relatively high speed) and parts of route used for refuse collection (relatively slow speed and multiple start-stops). The simulation was performed over the defined drive cycles and the energy requirements over the two-week cycle for domestic operations was calculated at $4,126 \mathrm{kWh}$.

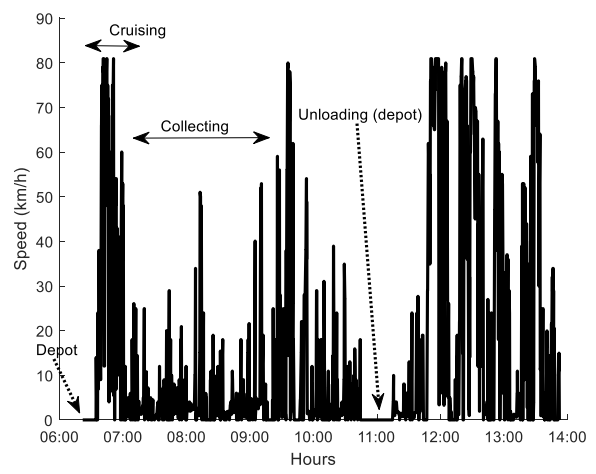

Fig. 8. Speed profile of domestic route performed on Day 11 by RCV no 2

A performance overview of this category was performed to examine the trade-off between the number of CoSP relative to the necessary capacity of the on-board battery. The initial assumption was that any charging en-route had to be accomplished without changing the duration of stops in the drive cycle as measured. With this assumption and by contrast with the Park and Ride bus routes, the size of the battery does not change significantly with the introduction of additional CoSP. This is mainly because the vehicles do not stop long enough at any common locations where a CoSP would deliver a useful charging boost to all vehicles. Hence, the OnC electrification solution is the most cost-effective option. Such a system involves eight eRCVs with a $180 \mathrm{kWh}$ on-board battery in each, designed to meet the energy requirement of the most demanding route with recharging overnight at the depot.

The required $180 \mathrm{kWh}$ on-battery weights $1,440 \mathrm{~kg}$ according to the $8 \mathrm{~kg} / \mathrm{kWh}$ specific energy. This, corresponds to an extra mass of $800 \mathrm{~kg}$ on the vehicle, assuming a $400 \mathrm{~kg}$ saving due to lighter electric motor and transmission system and a $250 \mathrm{~kg}$ saving from removing the fuel tank (capacity of 250 litres). This means that an eRCV would have lower payload capacity by approximately $800 \mathrm{~kg}$ in comparison with a conventional vehicle.

An alternative strategy is to allow the duration of same stops to be increased slightly to make the CoS approach to be a more effective solution. This would allow eRCVs to get a charging boost along their routes and reduce the size of the on-board battery. Such modifications to the drive cycles of refuse collection operations are less critical than for buses, as RCVs do not follow strict timetables. The analysis shows that domestic refuse collection operations share common segments of road where a possible CoSP could deliver sufficient energy to a number of eRCVs. The necessary capacity of the on-board battery drops to $80 \mathrm{kWh}$, requiring a number of stops to be extended by 5 min during the shift. However, this approach might impose practical challenges to existing operations. Depending on the route, it might be necessary to allow $5 \mathrm{~min}$ charging boost every time the vehicle travels by the charging location. This would probably not cause difficulty unless a number of different RCVs needed to use the same charger simultaneously, causing queuing delays. Solving this problem would require detailed knowledge of the individual RCV timetables, which should be a topic for further research.

A further alternative would be to allow 5-10 min charging at the depot when the vehicles are unloading, but with no additional stops en-route. This approach reduces the capacity of the on-board battery from $180 \mathrm{kWh}$ to $110 \mathrm{kWh}$, which is larger than the lowest possible capacity of $80 \mathrm{kWh}$ for CoS. However, it eliminates any practical issues as a single 5-10 min additional stop duration at the depot would be more attractive for both drivers and logistic operators. The unloading area is located within the site of the depot.

The three possible charging infrastructures for Domestic Waste Operations, which are the i) $\mathrm{OnC}$, ii) $\mathrm{CoS}$ and iii) CoSP at the depot, are compared in TABLE 7. The CoS option appears to be the most financially attractive solution without reducing the carrying capacity of the vehicle. The added mass due to on-board battery is compensated by the lighter electric motor, transmission system and fuel tank compared with a conventional vehicle. Yet, it might impose practical challenges that may undermine the efficiency of the system. Charging at the depot during unloading it is further assumed in this study.

Overall, an electrified system for domestic refuse collection operations include eight $\mathrm{eRCV}$ with a $110 \mathrm{kWh}$ on-board battery. This size reduces the carrying capacity of vehicles by $230 \mathrm{~kg}$ (taking into consideration the $650 \mathrm{~kg}$ savings), which corresponds to about 1.5 bins of waste (assuming $160 \mathrm{~kg}$ apiece). $15 \mathrm{~kW}$ chargers are needed at the depot for each vehicle for overnight charging based on a minimum of 7-hour 
recharging period. If needed, vehicles could a get charging boost from a $165 \mathrm{~kW}$ charger during unloading (based on a $1.5 \mathrm{C}$ charge rate for the $110 \mathrm{kWh}$ battery).

Such a system is expected to cost $£ 3.1$ million, based on the cost assumptions presented earlier in TABLE 4 (it is assumed that an eRCV would cost the same as an eBus which is valued at $£ 375 \mathrm{k})$. Indeed, modification of drive cycles combined with the introduction of the CoSP at the depot reduces the overall cost of the system by $£ 300 \mathrm{k}$ in comparison with the OnC solution. The cost savings from the smaller batteries are larger than the additional cost needed for the extra charging infrastructure at the unloading area.

TABLE 7

DOMESTIC WASTE - POSSIBLE CHARGING INFRASTRUCTURE

\begin{tabular}{lccc}
\hline \hline & OnC & CoS & CoSP at the depot \\
\hline Battery $(\mathrm{kWh})$ & 180 & 80 & 110 \\
Depot Charger $(\mathrm{kW})$ & 20 & 10 & 15 \\
CoSP $(\mathrm{kW})$ & NA & 120 & 165 \\
Cost $(£ \mathrm{~m})$ & 3.4 & 2.9 & 3.1 \\
Reduced Capacity $(\mathrm{kg})$ & 790 & 0 & 230 \\
\hline \hline
\end{tabular}

\section{B. City's Waste Collection Operations}

The same analysis was followed for all refuse collection operations of the city and the energy requirements, battery needed, capital costs and $\mathrm{CO}_{2}$ emission savings are summarised in TABLE 8.

The OnC solution is best for the Bin Collection operations at the city of Cambridge. The cost for installing a CoSP, even with modified drive cycles, is larger than the potential savings from using smaller batteries on-board (only one vehicle is used). By contrast, the installation of a CoSP at the unloading area combined with an additional stop duration of $5 \mathrm{~min}$ is the best solution for Dry Recycling operations. The necessary capacity of the on-board battery is reduced substantially from $160 \mathrm{kWh}$ to $110 \mathrm{kWh}$. Green Recycling vehicles can perform all routes with only overnight charging and finally, the introduction of a CoSP at the unloading area of Trade vehicles combined with an additional 5 min stop is financially the most attractive solution for Trade operations. The battery of these vehicles drops from $210 \mathrm{kWh}$ to $110 \mathrm{kWh}$ which results in significant cost savings. In total, three $165 \mathrm{~kW}$ CoSP are needed at the unloading areas for Domestic, Dry Recycling and Trade Waste operations.

TABLE 8

PERFORMANCE OVERVIEW OF REFUSE COLLECTION OPERATIONS

\begin{tabular}{lcccccc}
\hline \hline Operation & $\begin{array}{c}\text { Annual } \\
\text { Energy } \\
(\mathrm{MWh})\end{array}$ & $\begin{array}{c}\text { Annual } \\
\text { Mileage } \\
\left(10^{3} . \mathrm{km}\right)\end{array}$ & $\begin{array}{c}\text { No } \\
\mathrm{eRCV}\end{array}$ & $\begin{array}{c}\text { Battery } \\
(\mathrm{kWh})\end{array}$ & $\begin{array}{c}\text { Cost } \\
(£ \mathrm{~m})\end{array}$ & $\begin{array}{c}\mathrm{tCO}_{2} \\
\text { savings } \\
\text { by 2050 }\end{array}$ \\
\hline Domestic & 107.3 & 126 & 8 & 110 & 3.1 & 129 \\
Bin & 14.7 & 19 & 1 & 110 & 0.4 & 19 \\
Dry & 54.5 & 62 & 4 & 110 & 1.6 & 64 \\
Green & 32.7 & 46 & 2 & 110 & 0.8 & 47 \\
Trade & 124.7 & 170 & 9 & 110 & 3.4 & 174 \\
Total & 334 & 423 & 24 & - & 9.3 & 433 \\
\hline \hline
\end{tabular}

The daily power demand profile was calculated for the most demanding day during the two-week period when 23 refuse collection trips are performed across all categories of refuse operations. The profile is shown in Fig. 9. It is similar to a combination of the $\mathrm{OnC}$ and $\mathrm{CoS}$ profile of the Trumpington
Park and Ride bus route shown in Fig. 6. The power demand is constant in the early morning and late evening hours when vehicles are recharged in the depot. It fluctuates up to $200 \mathrm{~kW}$ during the day when charging boosts are needed during unloading. Although the power demand from a CoSP at the unloading area does not go above $165 \mathrm{~kW}$, it is noticed that $200 \mathrm{~kW}$ is drawn from the grid as some power is needed for overnight charging of other vehicles.

The peak power demand corresponds to an additional peak demand of $0.19 \%$ of the current power demand of Cambridge. Similarly, the extra load of $334 \mathrm{MWh}$ per year for such a system (TABLE 8 ) represents an additional load of only $0.04 \%$.

The average $\mathrm{CO}_{2}$ emissions of a conventional $26 \mathrm{t}$ diesel vehicle is around $1,056 \mathrm{gCO} / \mathrm{km}$ based on the real fuel economy of $39.21 / 100 \mathrm{~km}$ (obtained from the operator). The average energy consumption of eRCV was calculated as $0.79 \mathrm{kWh} / \mathrm{km}$ (TABLE 8 ). Assuming $300 \mathrm{gCO} / \mathrm{kWh}$ for the electricity grid in 2017 and $40 \mathrm{gCO}_{2} / \mathrm{kWh}$ in 2050 , the impact would be a significant $78-97 \%$ reduction of $\mathrm{CO}_{2}$ emissions in comparison with refuse collection functions by diesel vehicles.

The impact would be to save $347 \mathrm{tCO}_{2}$ per year at today's emissions rates and $433 \mathrm{tCO}_{2}$ per year by 2050 . This corresponds to accumulated savings of $13 \mathrm{ktCO}_{2}$ between 2018 and 2050 (based on a $0.7 \%$ annual increase rate each year between 2018 and 2050).

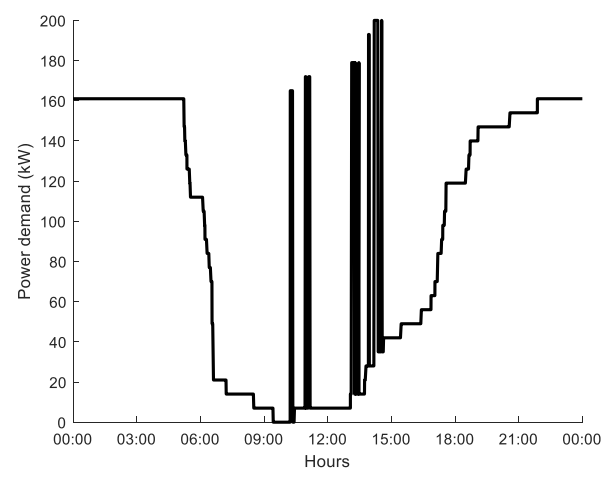

Fig. 9. Daily power demand profile for Cambridge refuse collection

\section{CAse Study: Home Deliveries}

In this section, the home delivery operations of two grocery suppliers at Cambridge are explored. A light goods vehicle up to $3.5 \mathrm{t}$ overall mass was monitored for each retailer using the SRF Logger. The Advisor eVan model (TABLE 1) was used to calculate the energy requirements over the logged drive cycles. No data was available about the cargo load of the vehicles and therefore, it is assumed that vehicles are half loaded in average throughout the journey reaching an overall mass of $2.8 \mathrm{t}$. Moreover, a $2 \mathrm{~kW}$ constant load was included in the analysis to model the power drawn from the refrigeration unit.

The results for each vehicle are summarised in TABLE 9 over a one-week cycle. It can be seen that Retailer B generally travels further than Retailer A because many of Retailer B's customers are in nearly villages; whereas Retailer A's customers are mainly concentrated in the city centre. Fig. 10 shows the drive cycle of the most demanding route over the one-week cycle, performed by Retailer B. 
TABLE 9

PERFORMANCE OVERVIEW OF HOME DELIVERY OPERATIONS

\begin{tabular}{lcc}
\hline \hline & Retailer A & Retailer B \\
\hline Max daily energy $(\mathrm{kWh})$ & 26 & 49 \\
Average daily energy $(\mathrm{kWh})$ & 22 & 34 \\
Aver. daily distance $(\mathrm{km})$ & 47 & 63 \\
Aver. Energy $(\mathrm{kWh} / \mathrm{km})$ & 0.47 & 0.55 \\
Annual energy $(\mathrm{MWh})$ & 8.1 & 12.6 \\
Annual mileage $\left(10^{3} \cdot \mathrm{km}\right)$ & 17 & 23 \\
tCO2 savings 2018 & 2 & 3 \\
tCO2 savings 2050 & 5 & 6 \\
Capital Cost (£k) & 220 & 310 \\
\hline \hline
\end{tabular}

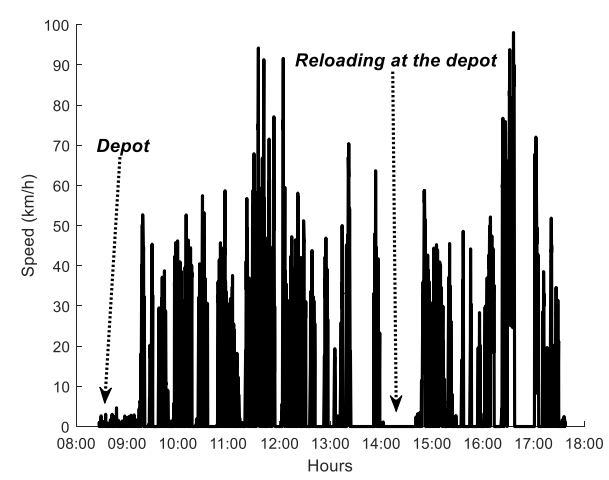

Fig. 10. Home delivery performed by Retailer B - speed profile

The unladed mass of the vehicle has to be similar when replacing a conventional vehicle with an eVan. This assures that the same amount of cargo could be delivered by both vehicles without violating the upper limit of $3.5 \mathrm{t}$. In that case, the mass savings from the lighter electric motor and transmission system compensates the mass of the on-board battery. In particular, an eVan is likely to be lighter by $355 \mathrm{~kg}$ in comparison with a conventional vehicle, based on a $300 \mathrm{~kg}$ saving due to lighter electric motor and transmission system (Advisor) and a $55 \mathrm{~kg}$ saving from not carrying the typical 55 litre fuel tank [37]. Consequently, a $45 \mathrm{kWh}$ on-board battery was proposed for eVans, based on the specific energy of $8 \mathrm{~kg} / \mathrm{kWh}$.

The OnC electrification option was proposed for Retailer A. The proposed battery of $45 \mathrm{kWh}$ is sufficiently big to provide the energy needed for the most demanding day. The batteries SOC do not go below the recommended safety margin of $20 \%$ and they get fully recharged overnight at the depot (store). Based on a minimum recharging time of 10 hours (based on the logged data), $3 \mathrm{~kW}$ power chargers are needed at the depot for each vehicle.

Up to four delivery vans are used every day, according to the supplier. This means that the power demand at the depot during the night is expected to increase by $12 \mathrm{~kW}$. No upgrade is needed to the electricity supply network of the store for meeting the new additional demand.

The cost assumptions of TABLE 4 were used in this section as well. The cost of eVans was assumed as $£ 35 \mathrm{k}$ per vehicle ${ }^{2}$. An electrified system for Retailer A, which includes four eVans with a $45 \mathrm{kWh}$ on-board battery and four $3 \mathrm{~kW}$ chargers for overnight charging, would cost $£ 220 \mathrm{k}$.

\footnotetext{
${ }^{2}$ Based on the Nissan E-NV200 electric light good vehicle which costs $£ 20 \mathrm{k}$ [37]. Increasing the battery from $24 \mathrm{kWh}$ to $45 \mathrm{kWh}$ (as it is recommended in this study) would add approximately $£ 10 \mathrm{k}$ to the current
}

As shown in TABLE 9, the suggested $45 \mathrm{kWh}$ battery is not adequate to deliver the daily energy needed by the vehicles of Retailer B. The CoS electrification approach has to be adopted for that case using chargers located at the depot. The analysis showed that the installation of one CoSP at the depot would deliver sufficient charging boost to the eVans during loading. A CoSP at the depot is used to fully recharge the vehicle during reloading which lasts approximately for $45 \mathrm{~min}$. The power transfer rate of the charger is $68 \mathrm{~kW}$, based on the maximum charge rate of $1.5 \mathrm{C}$. Vehicles return to the depot with SOC levels as high as $80 \% .3 \mathrm{~kW}$ chargers are needed for each eVan to fully recharge the batteries overnight. The capital cost for this system, including four vehicles plus chargers, was calculated at $£ 310 \mathrm{k}$ based on the cost assumptions of TABLE 4 .

Retailer B uses up to four vehicles per day. The daily power demand profile is similar in form to the power demand of refuse collection operations in Fig. 9. The demand is constant during early morning and late evening hours at $12 \mathrm{~kW}(4 \mathrm{eVans} \mathrm{X}$ $3 \mathrm{~kW}$ chargers) and fluctuates up to $76 \mathrm{~kW}$ during the day (due to the CoSP at the depot). The additional peak demand of $76 \mathrm{~kW}$ represents only $0.07 \%$ of the current peak demand of the city. The combined additional load of both retailers was calculated at 21.4 MWh per year as shown in TABLE 9. This corresponds to an insignificant load of less than $0.01 \%$ based on the current electricity consumption of Cambridge.

The average $\mathrm{CO}_{2}$ emissions of a conventional $3.5 \mathrm{t}$ diesel vehicle is around $300 \mathrm{gCO} / / \mathrm{km}$ based on the computed equivalent fuel economy of 11 1/100 km. The average energy consumption of each eVan was calculated as $0.51 \mathrm{kWh} / \mathrm{km}$. Assuming $300 \mathrm{gCO}_{2} / \mathrm{kWh}$ for the electricity grid (2017 levels), this corresponds to $153 \mathrm{gCO} / \mathrm{km}$ and represents a substantial reduction of $49 \%$. Using the national objectives for 2050 levels, reduction of $93 \% \mathrm{CO}_{2}$ emissions is feasible.

The impact would be to save $5 \mathrm{tCO}_{2}$ per year at today's emissions rates and $11 \mathrm{tCO}_{2}$ per year by 2050 . This corresponds to accumulated savings of $252 \mathrm{tCO}_{2}$ between 2018 and 2050 .

\section{RESULTS FOR THE CITY}

\section{A. Routes with available data}

In this section, the results are scaled up for the entire city and the implications for the electricity supply network are explored. The impact of a total shift towards electric road freight operations in Cambridge, which involves electrification of all bus routes, refuse collection and home delivery operations, is summarised in TABLE 10. This assumes that the explored bus routes, refuse collection and home delivery operations, which were investigated in this study, account $20 \%$ (in total 100 buses in Cambridge), $100 \%$ and $20 \%$ (in total 10 retailers in Cambridge) respectively of all city's operations.

The shift towards these electric road freight operations would increase the peak power demand of the city by $7.6 \mathrm{MW}(7.2 \%$ of the current peak). In terms of energy, the additional load was calculated at $16.1 \mathrm{GWh}$ per year ( $2 \%$ of current consumption).

price $(45-24 k W h) \times 500^{£} / k W h=£ 10.5 k$. This combined with the installation of a special refrigerated body around $£ 5 k$, the overall cost of the vehicle would be $£ 35 \mathrm{k}$. 
TABLE 10

OVERVIEW OF ELECTRIC ROUTES AT CAMBRIDGE

\begin{tabular}{|c|c|c|c|c|c|c|}
\hline & \multicolumn{2}{|c|}{ Demand } & \multicolumn{2}{|c|}{ Annual Load } & \multirow{2}{*}{$\begin{array}{c}\mathrm{ktCO}_{2} \\
\text { savings } \\
\text { by } \\
2050 \\
\end{array}$} & \multirow{2}{*}{$\begin{array}{c}\text { Capital } \\
\text { Cost } \\
£ \mathrm{~m}\end{array}$} \\
\hline & $\mathrm{kW}$ & $\begin{array}{c}\% \text { of } \\
\text { current }\end{array}$ & MWh & $\begin{array}{c}\% \text { of } \\
\text { current }\end{array}$ & & \\
\hline eBuses & 7,000 & 6.60 & 15,705 & 1.96 & 190 & 45.5 \\
\hline eRCVs & 200 & 0.19 & 334 & 0.04 & 13 & 9.3 \\
\hline eVans & 380 & 0.36 & 104 & 0.01 & 1.3 & 2.7 \\
\hline Total & 7,580 & 7.15 & 16,143 & 2.02 & 204.3 & 57.5 \\
\hline
\end{tabular}

\section{B. Urban deliveries}

Data about urban deliveries was not collected in this study. Some assumptions were made to estimate the performance requirements for an electrified system at Cambridge.

In the future logistics model, described in [6], it is assumed that Urban deliveries are performed by transportation of goods between urban consolidation centres and stores within the boundaries of cities. LGVs and HGVs up to $10 \mathrm{t}$ are mainly exploited for this type of services and the journeys are mostly on urban roads. According to road traffic statistics in GB [38], 16.5 billion vehicle miles were travelled by LGVs on urban sections of road and 2.2 billion vehicle miles by HGVs; including various operations such as deliveries to grocery shops, cloth shops, parcel deliveries, etc. Based on the fact that the population of Cambridge is $0.2 \%$ of that of $\mathrm{GB}$, it is assumed that 33 million of these miles were travelled by LGVs in Cambridge and 4.4 million miles by HGVs.

The estimated traffic mileage combined with the $0.51 \mathrm{kWh} / \mathrm{km}$ energy consumption of LGVs (calculated in section $\mathrm{V}$ ) and $1.05 \mathrm{kWh} / \mathrm{km}$ of $\mathrm{HGVs}$ performing urban deliveries (calculated in [6]) result in an overall additional electricity demand of 34,500 MWh per year.

The additional power demand from electrified urban deliveries would depend on the exact charging infrastructure of the system which cannot be determined at this stage due to missing information, such as number of vehicles performing deliveries, length of routes, frequency of deliveries, etc. The power demand for eBuses was scaled up to estimate the power demand for electrified urban deliveries. Assuming that the same power usage profile is generated by the urban delivery vehicles as for the eBuses, then the peak power required by the delivery vehicles would be $14 \mathrm{MW}$ (because approximately twice as much energy is required by urban deliveries than eBuses).

The cost needed for an electrified system for urban deliveries was estimated at $£ 91$ million based on the calculated cost of $£ 45.5$ million for eBuses. The impact from an electrified system for urban deliveries in Cambridge would be to reduce $\mathrm{CO}_{2}$ emissions by $9 \mathrm{ktCO}_{2}$ per year at today's norms ${ }^{3}$ and by 18 $\mathrm{ktCO}_{2}$ per year by $2050^{4}$. An aggregate saving of $430 \mathrm{ktCO}_{2}$ is calculated over the intervening period.

\section{City Overview}

Overall, the impact of total shift towards EVs at Cambridge in the long-term, which includes electrification of all bus routes, refuse collection vehicles, home deliveries and urban deliveries

\footnotetext{
${ }^{3}$ Assuming 33 million miles by LGVs and 4.4 million miles by HGVs; $300 \mathrm{gCO}_{2} / \mathrm{km}$ for a conventional LGV and $420 \mathrm{gCO}_{2} / \mathrm{km}$ for a conventional
}

is summarised in TABLE 11.

The total power demand for the city of Cambridge is calculated at $21.6 \mathrm{MW}$ (20\% of the current peak) and the additional energy consumption at approximately $51 \mathrm{GWh}$ per year ( $6 \%$ of current consumption). Nevertheless, the anticipated installed generating capacity and generation of electricity in GB (and in cities) is estimated to increase by $145 \%$ [39] and $200 \%$ [32] respectively. This allows a considerable margin for the electrification of transportation.

The total capital cost needed for such a project is calculated at $£ 149$ million which is lower to the cost of the Cambridge Guided Busway (£200 million) [40]. The impact would be a significant aggregate saving of $635 \mathrm{ktCO}_{2}$ by 2050 .

TABLE 11

OVERVIEW OF ELECTRIC ROAD FREIGHT AT CAMBRIDGE

\begin{tabular}{|c|c|c|c|c|c|c|}
\hline & \multicolumn{2}{|c|}{ Demand } & \multicolumn{2}{|c|}{ Annual Load } & \multirow{2}{*}{$\begin{array}{c}\mathrm{ktCO}_{2} \\
\text { savings } \\
\text { by } \\
2050\end{array}$} & \multirow{2}{*}{$\begin{array}{c}\text { Capita } \\
\text { Cost } \\
£ \mathrm{~m}\end{array}$} \\
\hline & $\mathrm{kW}$ & $\begin{array}{l}\% \text { of } \\
\text { current }\end{array}$ & MWh & $\begin{array}{c}\% \text { of } \\
\text { current }\end{array}$ & & \\
\hline $\begin{array}{l}\text { Routes } \\
\text { with data }\end{array}$ & 7,580 & 7.2 & 16,143 & 2.0 & 205 & 57.5 \\
\hline $\begin{array}{l}\text { Urban } \\
\text { Deliveries }\end{array}$ & 14,000 & 13.2 & 34,500 & 4.3 & 430 & 91 \\
\hline Total & 21,580 & 20.4 & 50,643 & 6.3 & 635 & 149 \\
\hline
\end{tabular}

\section{CONCLUSIONS}

A charging infrastructure for electric road freight operations was explored in this paper including the auxiliary services for buses and refuse collection functions. The city of Cambridge UK was chosen for demonstration. The five Park and Ride bus routes, the refuse collection operations and two home delivery operations were investigated. Real data about existing operations was collected to define accurate drive cycles.

It was shown that the $\mathrm{CoS}$ approach appears to be the best solution for electrifying the Park and Ride bus routes of the city. Such a system requires an on-board battery of practical size (around $135 \mathrm{kWh}$ on average for all Park and Rides), charging points at either end of each route and less powerful chargers at the depot to fully recharge the vehicles overnight. This system would cost $£ 9.1$ million and would result to an accumulated $\mathrm{CO}_{2}$ emission savings of $38 \mathrm{ktCO}_{2}$ between 2018 and 2050.

A combination of the $\mathrm{CoS}$ and $\mathrm{OnC}$ approach was considered to be the most appropriate solution for electrifying the refuse collection operations of Cambridge. In such a system, the $110 \mathrm{kWh}$ on-board battery of vehicle would be large enough to provide all the energy needed for the entire day. Yet, it has a practical size which does not compromise the capacity of the vehicles. For some routes, it would be necessary to recharge the vehicles during unloading at the depot before performing the second part of the shift. It was shown that three $165 \mathrm{~kW}$ charging points installed at the depot (one charger for each of the Domestic, Dry Recycling and Trade vehicles) combined occasionally with an additional 5-10 min stop during unloading would deliver sufficient charging boost to the vehicles. A total

$\mathrm{HGV} ; 153 \mathrm{gCO}_{2} / \mathrm{km}$ for an electric LGV $\left(0.51 \mathrm{kWh} / \mathrm{km} \mathrm{X} 300 \mathrm{gCO}_{2} / \mathrm{kWh}\right)$ and $315 \mathrm{gCO}_{2} / \mathrm{km}$ for an electric $\mathrm{HGV}\left(1.05 \mathrm{kWh} / \mathrm{km} \mathrm{X} 300 \mathrm{gCO}_{2} / \mathrm{kWh}\right)$

${ }^{4}$ Based on $40 \mathrm{gCO}_{2} / \mathrm{kWh}$ by 2050 
capital cost of $£ 9.3$ million was computed for this system and $13 \mathrm{ktCO}_{2}$ emission savings are possible by 2050 .

For the case of home deliveries, it was shown that a $45 \mathrm{kWh}$ on-board battery would provide the needed energy for the entire day. If needed, a charging point could be installed at the depot (store) and recharge the batteries of the vehicles during reloading. The combined system would cost $£ 0.53$ million and would save up to $0.25 \mathrm{ktCO}_{2}$ by 2050 .

The results were scaled up for the entire city and combined with estimated performance requirements for urban deliveries. It was shown that a total shift towards electric freight vehicles at Cambridge would increase the power demand of the city by $21.6 \mathrm{MW}$ (20.4\% of the current peak) and the energy consumption by $50.6 \mathrm{GWh}$ per year $(6.3 \%$ of current consumption). Nevertheless, the installed generating capacity and generation of electricity in GB is estimated to increase by $145 \%$ and $200 \%$ respectively. This allows a considerable margin for the electrification of freight transportation. The total capital cost needed for such a project was calculated at $£ 149$ million which is similar to the cost of other city's projects like the Cambridge Guided Busway. The impact would be a significant aggregate saving of $635 \mathrm{ktCO}_{2}$ by 2050 .

\section{ACKNOWLEDGMENT}

This research was supported by the i) EPSRC Grant EP/K00915X/1: 'Centre for Sustainable Road Freight Transport' and the ii) EPSRC Doctoral Training Award 1497982: 'Wireless Electric Charge-on-the-move: An appraisal for the UK transport application'.

Special thanks to Dr Xiaoxiang Na for his research on the 'SRF Logger' for in-service monitoring of road vehicles.

\section{REFERENCES}

[1] J. King, "The King Review of low-carbon cars," Report, 2007.

[2] UPS, "Sustainability Report," 2015. [Online]. Available: https://sustainability.ups.com/media/ups-pdf-interactive/index.html.

[3] DECC, "UK Greenhouse Gas Emissions," Report, 2017.

[4] A. M. C. Odhams, R. L. Roebuck, Y. J. Lee, S. W. Hunt, and D. Cebon, "Factors influencing the energy consumption of road freight transport," Proc. Inst. Mech. Eng. Part C J. Mech. Eng. Sci., vol. 224, no. 9, pp. 1995-2010, Sep. 2010.

[5] P. Greening, M. Piecyk, A. Palmer, and A. McKinnon, "An assessment of the potential for demand-side fuel savings in the Heavy Goods Vehicle (HGV) sector," Centre for Sustainable Road Freight Technical Report: CUED/C-SRF/TR08, 2015.

[6] D. Nicolaides, D. Cebon, and J. Miles, "Prospects for electrification of freight transportation,” IEEE Syst. J., vol. 12, no. 2, pp. 1838-1849, 2017.

[7] D. Nicolaides and J. Miles, "Wireless Electric Charge-on-the-move: A sustainability appraisal of the potential for the UK transport application,” J. Multidiscip. Eng. Sci. Technol., vol. 2, no. 8, pp. 2238 2246, 2015.

[8] D. Nicolaides, R. McMahon, D. Cebon, and J. Miles, "A national power infrastructure for Charge-on-the-Move," in IEEE PELS Workshop on Emerging Technologies: Wireless Power, 2016, pp. 180-185.

[9] D. Nicolaides, R. McMahon, D. Cebon, and J. Miles, "A National Power Infrastructure for Charge-on-the-Move: An Appraisal for Great Britain," IEEE Syst. J., vol. PP, no. 99, pp. 1-9, 2018.

[10] D. Nicolaides and J. Miles, "Wireless Electric Charge-On-The-Move: An Economic Appraisal of the Potential for the UK Transport Application," in International Conference on Transportation and Civil Engineering, 2015, pp. 53-59.
[11] J. M. Miller, P. T. Jones, J.-M. Li, and O. C. Onar, "ORNL Experience and Challenges Facing Dynamic Wireless Power Charging of EV's," IEEE Circuits Syst. Mag., vol. 15, no. 2, pp. 40-53, Jan. 2015.

[12] J. T. Boys and G. A. Covic, "The Inductive Power Transfer Story at the University of Auckland," IEEE Circuits Syst. Mag., vol. 15, no. 2, pp. 6-27, Jan. 2015.

[13] T. M. Fisher, K. B. Farley, Y. Gao, H. Bai, and Z. T. H. Tse, "Electric vehicle wireless charging technology: a state-of-the-art review of magnetic coupling systems," Wirel. Power Transf., pp. 1-10, Sep. 2014.

[14] Milton Keynes Council, "Electric Bus," 2012. [Online]. Available: https://www.milton-keynes.gov.uk.

[15] Siemens, "Charging Systems for ebuses," 2017. [Online]. Available: https://www.siemens.com/global/en/home/products.html.

[16] ABB, "Opportunity charging for electric buses," 2017. [Online]. Available: http://new.abb.com/ev-charging/products/.

[17] Smart Cambridge, "Smart Cambridge: Solutions for the city and beyond," 2017. [Online]. Available: http://www.connectingcambridgeshire.co.uk.

[18] Masternaut, "The smarter fleet platform." [Online]. Available: http://www.masternaut.co.uk/UkWebSite/.

[19] A. Brooker, K. Haraldsson, T. Hendricks, V. Johnson, K. Kenneth, B. Kramer, T. Markel, M. O'Keefe, S. Sprik, K. Wipke, and M. Zolot, “ADVISOR Advanced Vehicle Simulator," NREL, 2013. [Online]. Available: http://adv-vehicle-sim.sourceforge.net/.

[20] R. D. Senger, "Validation of ADVISOR as a Simulation Tool for a Series Hybrid Electric Vehicle Using the Virginia Tech FutureCar Lumina," Virginia Tech, 1997.

[21] K. B. Wipke, M. R. Cuddy, and S. D. Burch, "ADVISOR 2.1: a userfriendly advanced powertrain simulation using a combined backward/forward approach,” IEEE Trans. Veh. Technol., vol. 48, no. 6, pp. 1751-1761, 1999.

[22] Air Resources Board, "Battery Cost for Heavy-Duty Electric Vehicles," California Environmental Protection Agency Report, 2016.

[23] D. Nicolaides, "Power Infrastructure Requirements for Road Transport Electrification," $\mathrm{PhD}$ Thesis, Department of Engineering University of Cambridge, 2018

[24] Battery University, "Charging Lithium-ion," 2017. [Online]. Available: http://batteryuniversity.com/learn/article/charging_lithium_ion_batteries

[25] BYD, "BYD eBus," 2017. [Online]. Available: http://www.byd.com/la/auto/ebus.html.

[26] INTIS, "EVs Unplugged," IHS-Automotive Hybrid-EV Anal., vol. 6, no. 5, pp. 8-11, 2015.

[27] Plugless, "Wireless electric vehicle charging," 2017. [Online]. Available: https://www.pluglesspower.com/.

[28] J. Brodie, "BMW previews wireless charging for 2018," AutoExpress, 2017. [Online]. Available: http://www.autoexpress.co.uk/bmw/5series/101091/bmw-previews-wireless-charging-for-2018-on-530eiperformance.

[29] podPoint, "Home Charging," 2017. [Online]. Available: https://podpoint.com/products/homecharge.

[30] National Grid, "Winter Outlook Report 2017/2018," Report, 2017.

[31] National Statistics, "Overview of the UK population: March 2017," Report, 2017.

[32] DECC, “2050 Pathways Analysis,” Report URN 10D/764, UK, 2010.

[33] EIA, "How much carbon dioxide is produced by burning gasoline and diesel fuel?," 2016. [Online]. Available: http://www.eia.gov/tools/faqs/faq.cfm?id=307\&t=11.

[34] Electricity Info, "Real Time British Electricity Fuel Mix." [Online]. Available: http://electricityinfo.org/real-time-british-electricity-supply/.

[35] DECC, "Updated Energy and Emissions Projections 2017," Report, 2018.

[36] UK Parliament, "The UK power sector: trends and targets," Emissions Performance Standards - Energy and Climate Change, 2010. [Online]. Available: https://publications.parliament.uk

[37] Nissan, "E-NV200," 2018. [Online]. Available: https://www.nissan.co.uk/vehicles/new-vehicles/e-nv200-combi.html.

[38] DfT, "Road traffic estimates in Great Britain," Report, 2017.

[39] G. Ault, D. Frame, N. Hughes, and N. Strachan, "Electricity Network Scenarios for Great Britain in 2050," Final Report for Ofgem's LENS project (Ref. No. 157a/08), London: Ofgem, 2008.

[40] Cambridge County Council, "Population, Housing and Employment Forecasts," Report, 2013.

[41] BEIS, "Electricity Generation Costs," Report, London, 2016.

[42] Ofgem, "The revenues, costs and profits of the large energy companies in 2013," Report, London, 2014. 